\title{
Analysis of the compatibility of dental implant systems in fibula free flap reconstruction
}

\author{
Ramin Carbiner ${ }^{1,2}$, Waseem Jerjes ${ }^{3,4,5}$, Kaveh Shakib ${ }^{6}$, Peter V Giannoudis ${ }^{4,5}$ and Colin Hopper ${ }^{1,2,3^{*}}$
}

\begin{abstract}
As a result of major ablative surgery, head and neck oncology patients can be left with significant defects in the orofacial region. The resultant defect raises the need for advanced reconstruction techniques. The reconstruction in this region is aimed at restoring function and facial contour. The use of vascularised free flaps has revolutionised the reconstruction in the head and neck. Advances in reconstruction techniques have resulted in continuous improvement of oral rehabilitation. For example, endosteal implants are being used to restore the masticatory function by the way of prosthetic replacement of the dentition. Implant rehabilitation usually leads to improved facial appearance, function, restoration of speech and mastication. Suitable dental implant placement's site requires satisfactory width, height and quality of bone. Reconstruction of hard tissue defects therefore will need to be tailored to meet the needs for implant placement.

The aim of this feasibility study was to assess the compatibility of five standard commercially available dental implant systems (Biomet 3i, Nobel Biocare, Astra tech, Straumann and Ankylos) for placement into vascularised fibula graft during the reconstruction of oromandibular region.

Radiographs (2D) of the lower extremities from 142 patients in the archives of the Department of Radiology in University College London Hospitals (UCLH) were analysed in this study. These radiographs were from 61 females and 81 males. Additionally, 60 unsexed dry fibular bones, 30 right sided, acquired from the collection of the Department of Anatomy, University College London (UCL) were also measured to account for the 3D factor. In the right fibula (dry bone), $90 \%$ of the samples measured had a width of $13.1 \mathrm{~mm}$. While in the left fibula (dry bone), $90 \%$ of the samples measured had a width of $13.3 \mathrm{~mm}$. Fibulas measured on radiographs had a width of $14.3 \mathrm{~mm}$ in $90 \%$ of the samples. The length ranges of the dental implants used in this study were: 7-13 $\mathrm{mm}$ (Biomet 3i), 10-13 mm (Nobel biocare), 8-13 mm (Astra Tech), 8-12 mm (Straumann ) and 8-11 mm (Ankylos). This study reached a conclusion that the width of fibula is sufficient for placement of most frequently used dental implants for oral rehabilitation after mandibular reconstructive procedures.
\end{abstract}

\section{Introduction}

As a result of major ablative surgery, head and neck oncology patients can be left with significant defects in the orofacial region. The resultant defect raises the need for advanced reconstruction techniques. The reconstruction in this region is aimed at restoring function and facial contour. The use of vascularised free flaps has revolutionised the reconstruction in the head and neck. In addition to restoring structure, these flaps have reduced the adverse effects of tumour surgery on the patient's

\footnotetext{
* Correspondence: c.hopper@ucl.ac.uk

${ }^{1} \mathrm{Head}$ and Neck Centre, University College London Hospitals, London, UK ${ }^{2}$ Unit of Oral and Maxillofacial Surgery, UCL Eastman Dental Institute, London, UK

Full list of author information is available at the end of the article
}

oral function when compared to other reconstructive means. Advances in reconstruction techniques have resulted in continuous improvement of oral rehabilitation. For example, endosteal implants are being used to restore the masticatory function by the way of prosthetic replacement of the dentition. Implant rehabilitation usually leads to improved facial appearance, function, restoration of speech and mastication [1-16].

Several vascularised bone grafts have been used for the reconstruction of mandibular defects, such as the radius, metatarsus, thoracic rib, scapula, iliac crest, and fibula. Fibula free tissue transfer has demonstrated high reliability and adaptability for the reconstruction of those defects, due to its length (up to $25 \mathrm{~cm}$ ), long vascular pedicle and ability to be osteotomised to provide a favorable facial 
contour [17]. The fibula flap can be used as an osteomuscular flap or osteomyocutaneous flap. The advantage of the latter is to provide a simultaneous reconstruction of intraoral defects (i.e. cheek, palate, floor of the mouth) and cutaneous defects in the same area. Moreover, the fibular bone (due to its appropriate thickness and bicortical nature), can act as a viable recipient site for implant placement and subsequent implant-supported prosthesis [4].

The transfer of the osseofasciocutaneus vascularised fibula free flap has become a routine procedure in the reconstruction of comprehensive oromaxillofacial defects. The fibula flap is being increasingly used for both mandibular and maxillary reconstruction. Modifications of the harvesting techniques have improved the reliability of the skin pedicle extending the application of this flap, although both the bone and the skin must share the same alignment [18]. The deficit(s) at the donor site is limited, and most patients are not troubled by them (i.e. pain, cosmesis. . etc.). In contrast to the shape of the mandible, the fibula is a straight bone (Figure 1). A prime advantage of the fibula is that up to $270 \mathrm{~mm}$ in length may be harvested, allowing reconstruction of any length of mandibular defect. Besides its length, major advantages of the fibula free flap include the trigonal diameter of the fibular bone, with the additional advantage of bicortical anatomy which usually allows the placement of dental implants and facilitate osseointegration [18].

To restore mandibular anatomical continuity and configurations in the case of a mandibular defect, the fibula can be osteotomised at several places depending on the extent and location of the defect and used for reconstruction of the mandible [19]. An additional advantage is the option to harvest the fibula flap as an osseofasciocutaneous [2,20]. Although the skin paddle is suitable for oral reconstruction, it does not provide an appropriate peri-implant environment $[17,18]$. The resection of floor of mouth and alveolus carcinoma followed by reconstruction of the defect with free fibular flap is demonstrated in Figures 2, 3, 4, 5, $6,7,8$.

Optimal biomechanical and biochemical stimuli from the implant surface are of utmost importance for the bone healing process. The establishment and maintenance of a soft tissue seal around the transmucosal part of an implant (i.e. the abutment) is vital for implant treatment success $[21,22]$.

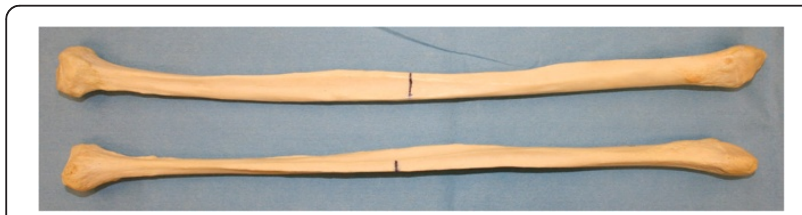

Figure 1 Left fibula bone (top) and a right fibula (bottom).

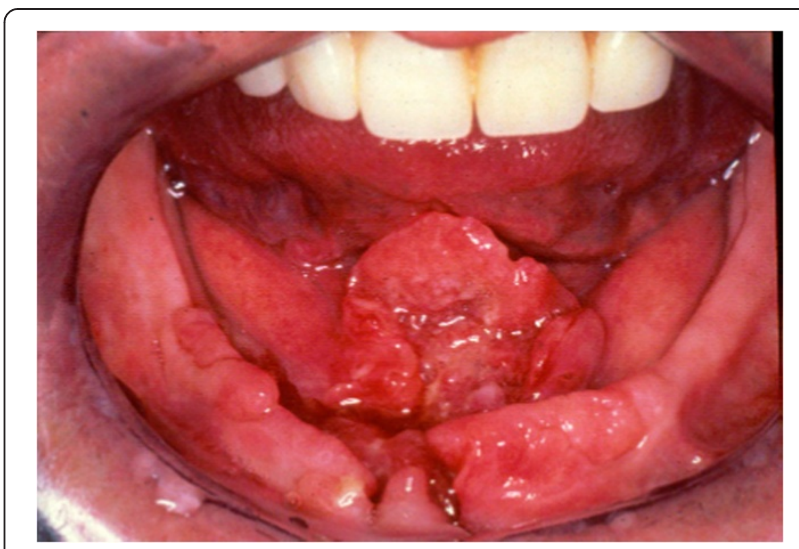

Figure 2 T4 SCC floor of mouth and alveolus.

There are more than 300 different dental implant systems in the market. The most frequently used in the reconstruction of the oromaxillofacial region include Biomet 3i, Nobel Biocare, Astra Tech, Straumann and Ankylos. Suitable dental implant placement's site requires satisfactory width, height and quality of bone. Reconstruction of hard tissue defects therefore will need to be tailored to meet the needs for implant placement.

The aim of this feasibility study was to assess the compatibility of five standard commercially available dental implant systems (Biomet 3i, Nobel Biocare, Astra tech, Straumann and Ankylos) for placement into vascularised free fibulagraft during the reconstruction of oromandibular region.

\section{Materials \& methods}

The protocol of this study was approved by the UCL/ UCLH Committee for Research Ethics Concerning Human Subjects.

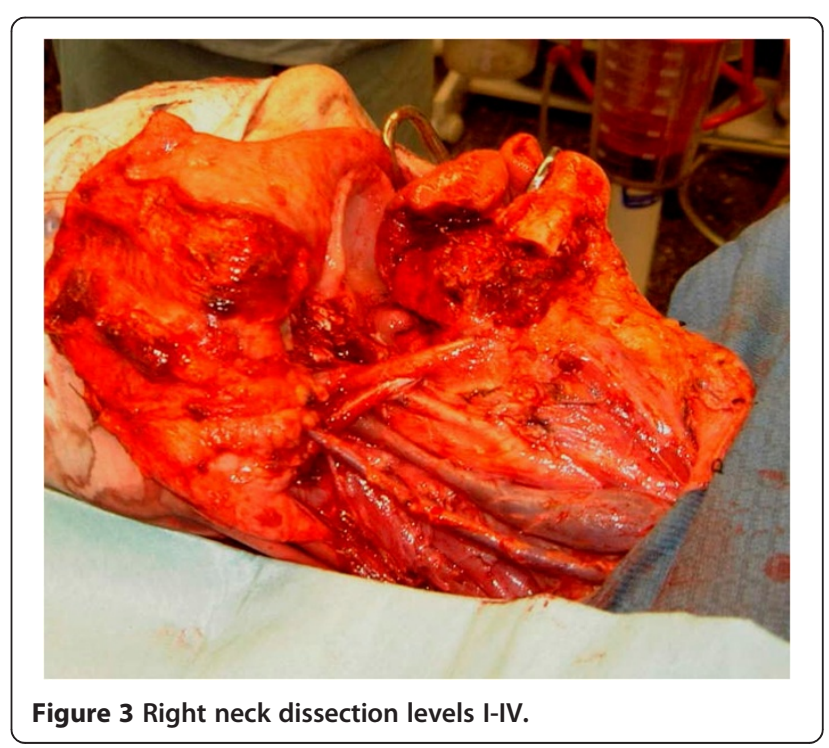




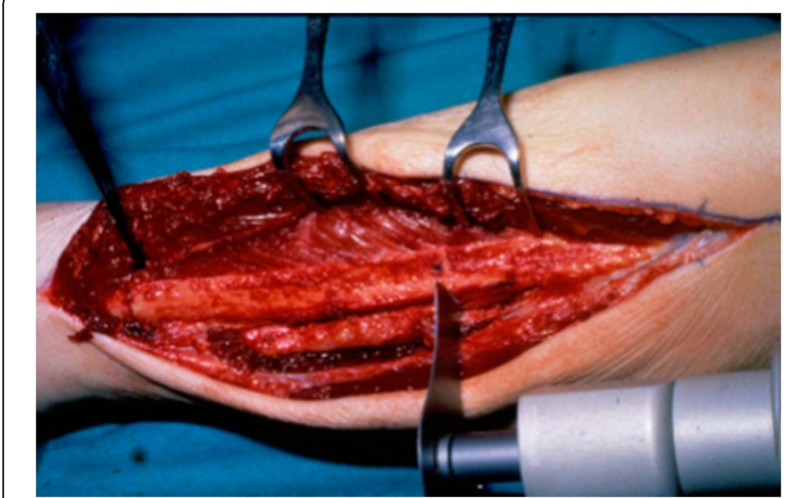

Figure 4 Dissected fibula ready for harvesting.

Anterio-posterior (AP) digital radiographs (2D) of the lower extremities from 142 patients from the Department of Radiology at UCLH were included in this study. These radiographs were from 61 females and 81 males. Radiographs were accessed through the UCLH Picture Archiving and Communication System (PACS). Measurements were acquired by using the tools provided by the PACS system (i.e. electronic ruler). Exclusion criteria were patients who had any history of fractures, longterm use of steroids, poor quality X-rays of the tibia or fibula and degenerative bone disease. The inclusion criteria were patients above eighteen years of age (Figure 9). The first step was to measure the fibular length on the radiograph; this was followed by registering the length midpoint and the width at the midpoint.

Sixty unsexed dry fibula bone, (30 right sided), were acquired from the specimens collection at the Department of Anatomy, UCL to account for the 3D factor. Fibula length and width measurement at the midpoint were acquired as in the previous cohort. Digital Verniar calliper was used to measure the width (Figure 1).

Five of the most frequently used dental implant systems, in oral and maxillofacial surgery, were assessed for their feasibility in restoring function in reconstructed

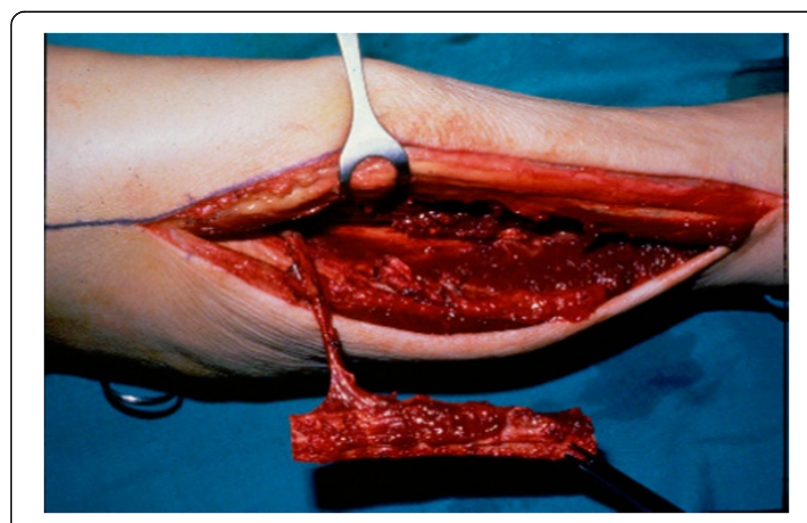

Figure 5 Harvested vascular fibular pedicle.

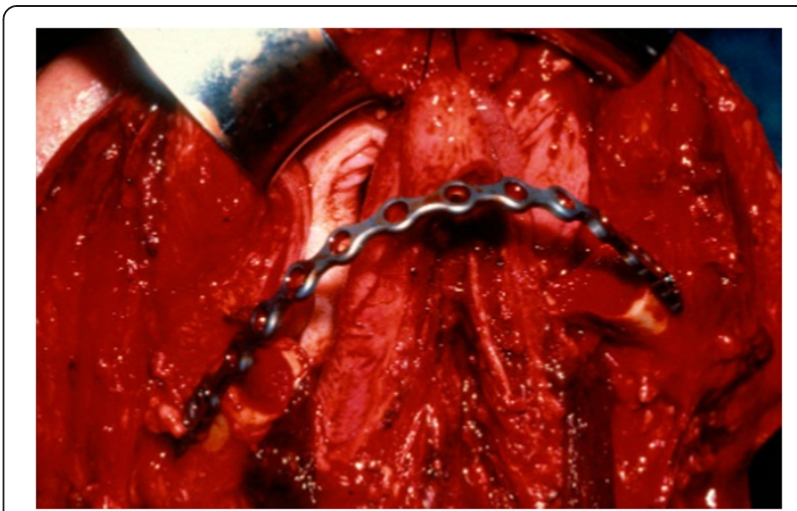

Figure 6 Reconstruction plate in place.

mandibles with vascularised fibula free flap. The measurements were obtained directly from the manufacturers and were not measured independently in this study.

\section{Statistical analysis}

Data were analysed using the software SPSS for windows (Version 14.0 SPSS). When plotted, the means were normally distributed and a two Sample $t$-test has been used to look for the differences between the two groups (male and female) in AP X- ray measurements and differences in the right and left dry bones. When a P-value $<0.001$ (or 0.1 percent) was reported, it was assumed that, since both samples were normally distributed, the difference was significant.

\section{Results}

Measurements taken from the 142 AP X-rays of the lower extremities showed the mean fibular length to be $399 \mathrm{~mm}$ (range male 339-446 $\mathrm{mm}$ and female 319- 436 $\mathrm{mm}$ ), while the mean of the registered midpoint of the fibular length was $194 \mathrm{~mm}$ (range: male 170-223 mm and female $160-218 \mathrm{~mm}$ ), the mean fibular width was 12 $\mathrm{mm}$ (range: male 9.4-17.4 $\mathrm{mm}$ and female 7.7-15.6 mm).

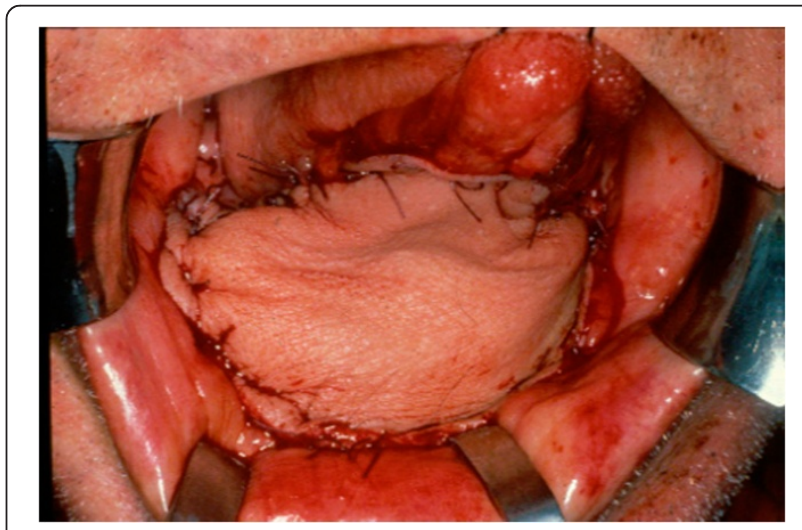

Figure 7 Anastomised fibular pedicle in placed. 


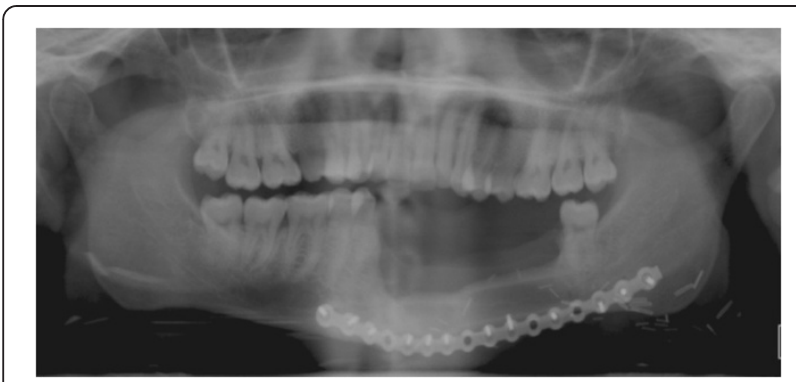

Figure 8 OPG shows a reconstructed mandible with vascularised fibula free flap after hemimandiblectomy as result of cancer surgery.

On radiographs, male fibulas were found to be significantly longer and wider (P-value $<0.001)$. Measurements of 60 unsexed dry fibular bones, showed the mean fibular length to be $360 \mathrm{~mm}$ (range 332-397 $\mathrm{mm}$ ), while the mean midpoint was $180 \mathrm{~mm}$ (range: $166-198 \mathrm{~mm}$ ), the mean fibular width at the registered midpoint was 10.5 $\mathrm{mm}$ (range: 6.67-14.2 $\mathrm{mm}$ ); there was no significant difference in the length or width when comparing the right to the left fibulas.

The mean widths of fibulas on X-rays were significantly higher than dry bone taking into consideration the magnification factor (on the radiographs). Based on gender, it was found that the widths of male fibulas measured on radiographs are significantly higher. A 2 sample $\mathrm{T}$ - test has been performed with $95 \%$ confidence interval

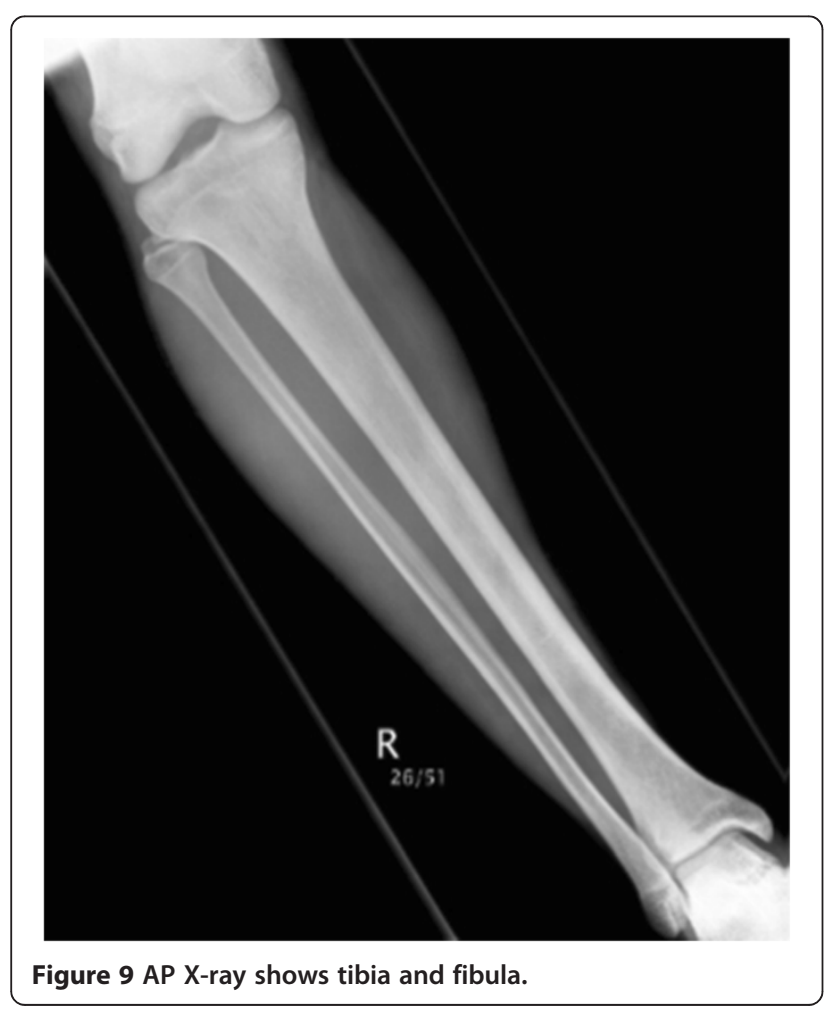

and showed a P-value of $0.772,0.779$ and 0.646 for the length, midpoint and width, respectively.

In the right fibula (dry bone), $90 \%$ of the samples measured had a width of $13.1 \mathrm{~mm}$. While in the left fibula (dry bone), 90\% of the samples measured had a width of $13.3 \mathrm{~mm}$; fibulas measured on radiographs had a mean width of $14.3 \mathrm{~mm}$ in $90 \%$ of the samples.

With regards to the dental implants, Astra implants varied in length from $8 \mathrm{~mm}$ to $19 \mathrm{~mm}$, while their diameter was from $3.5 \mathrm{~mm}$ to $5 \mathrm{~mm}$. Ankylos implants also varied in length from $8 \mathrm{~mm}$ to $17 \mathrm{~mm}$ with a diameter of 3.5-7 mm. While Straumann implants length was 8$16 \mathrm{~mm}$ with a diameter 3.3-4.8 $\mathrm{mm}$. Biomet 3i length can reach up to $20 \mathrm{~mm}$ with a diameter of 3.25-6 $\mathrm{mm}$. With Noble Biocare, the implant length varies from 10$15 \mathrm{~mm}$ while the width can reach up to $5 \mathrm{~mm}$. When comparisons are made, it was obvious that the width of fibula is sufficient for placement of most frequently used dental implants for oral rehabilitation after mandibular reconstructive procedures.

\section{Discussion}

Reconstruction of the oromandibular region following major resective surgery or severe comminuted facial fractures remains a complicated issue. The use of vascularised free tissue transfer with hard tissue, especially in vascularised fibula free flap, provides one of the best possibilities for full functional mandibular rehabilitation in combination with dental implants; whether such an approach should occur primarily in combination with the free flap reconstruction or in a later stage is debated; however many believe that it increases the survival of composite tissue flaps and enhances functional result $[1-16,23]$.

Two aspects regarding the relevance of this feasibility study need exploring. First, is the width of bone component of the free fibula flap sufficient to receive the most frequently used dental implants? And second, is there any alternative technique that could be employed to improve the height of the hard tissue in the fibula free flap for better prosthetic rehabilitation which will ultimately improve the patient's quality of life?

In our study, we looked at the compatibility of five different dental implant systems (namely: Biomet 3i, Nobel Biocare, Astra tech, Straumann and Ankylos) in fibula free flap reconstruction. A vertical bone height of 7-10 $\mathrm{mm}$ is frequently taken as the minimum bone height to be used for implant placement so for the purposes of this study, we established a minimum bone height criteria of $10 \mathrm{~mm}$. Numerous studies have concluded that $\geq 10 \mathrm{~mm}$ represents a sufficient bone thickness in mandibular reconstruction for safe osteointegrated implant placement [23]. Also, according to previous studies, an implant diameter range of $3.75-4.8 \mathrm{~mm}$ is suitable for 
placement in reconstructed mandible with fibula free flap $[18,24,25]$.

Fibular bones were measured on 142 AP X-rays taken from PACS radiographic database at UCLH and 60 unsexed dry bones at the Anatomy Department, UCL. The mean length, midpoint and width at the midpoint acquired from X-rays were $399 \mathrm{~mm}, 194 \mathrm{~mm}$ and $12 \mathrm{~mm}$, respectively; and for dry bone, they were $360 \mathrm{~mm}, 180 \mathrm{~mm}$ and $10.5 \mathrm{~mm}$, respectively, fibulas measured on radiographs had a width of $14.3 \mathrm{~mm}$ in $90 \%$ of the samples. Furthermore, $90 \%$ of the right fibula (dry bone) samples measured had a width of $13.1 \mathrm{~mm}$. While in the left fibula (dry bone), $90 \%$ of the samples measured had a width of $13.3 \mathrm{~mm}$.

The five implant systems sizes (length and diameter) were analysed and compared with the mean measurements of width of fibula on X-rays and dry bones. The outcome of the results revealed that any of the implant systems included in this study would allow the possibility of prosthetic rehabilitation. Also our results are in line with previous findings in the literature [23].

An important consideration in relation to fibula free flap and implantation is the irradiation delivered in most of the head and neck cancer patients in the immediate postoperative phase. After radiotherapy bone regeneration is depressed by $70.9 \%$ with a recovery of up to $28.9 \%$ in year one; the recommended time for attempting implantation is a minimum of 12 months after irradiation [17].

Reconstruction of mandibular defects following surgical ablation for tumours or after osteoradionecrosis with fibula free flaps has shown to be a reliable technique with good long-term prognosis. Implants placed in the reconstructed areas have been demonstrated to integrate normally with high success and survival rates when compared to those implants placed in native bone [4].

The creation of an adequate implant crown ratio with proper reconstruction of the alveolar processes, could improve implant position and angulations and consequently functional ability. The limited thickness of the fibular diaphysis prevents the use of implants longer than $10-12 \mathrm{~mm}$. This limitation can result in unfavourable implant crown ratio. An unfavourable implant crown ratio produces bending moments, possible screw loosening, component fracture, or even implant fracture. Also, aesthetic problems and difficulties in obtaining adequate oral hygiene may be present [26]. To achieve better implant crown ratio after autogenous reconstruction of the mandible with fibula free flap, different techniques have been suggested including the use of doublebarrelled reconstruction [27], distraction of the recipients site and additional free bone grafting, and corticocancellous iliac grafts.
In double-barrelled reconstruction, there is risk of blocking the blood supply to the graft which consequently causes flap failure. Distraction osteogenesis completely avoids problems like donor site morbidity, soft tissue limitations at the recipient site and unpredictable graft resorption [3,28-31].

A valid criticism of the method used in measuring the fibula is that $2 \mathrm{D}$ radiographs were used. This problem could have been avoided if 3 Dimensional Computed Tomography (3D CT) scans were used instead. However such scans were not available in significant numbers on the PACS radiographic database. The use of the dry skeleton was aimed in part to redress this shortcoming.

In addition, we must mention that so far there is no particular dental implant system specifically designed for the use in reconstructed mandible with fibula free flap. However all five dental implant systems included in this study were shown to be suitable for the placement in reconstructed mandible with fibula free flap.

To sum up, oromandibular reconstruction is a complex procedure with many available options. Mandibular defects could be better reconstructed with fibula free flap, with recognised improvements in the patient's prognosis (i.e. facial contour and function). We can conclude from this feasibility study that the width of fibula is sufficient for placement of the most frequently used dental implants for oral rehabilitation after mandibular reconstructive procedures. However for optimal prosthetic rehabilitation, distraction osteogenesis is preferred. Furthermore, doublebarreled reconstruction is one of the treatment options which give an instant increase in height of mandible for more precise placement of implant and possibility for an optimal oral rehabilitation.

\section{Competing interests}

The authors declare that they have no competing interests.

\section{Authors' contributions}

All authors contributed to conception and design, carried out the literature research, manuscript preparation and manuscript review. All authors read and approved the final manuscript.

\section{Author details}

${ }^{1}$ Head and Neck Centre, University College London Hospitals, London, UK. ${ }^{2}$ Unit of Oral and Maxillofacial Surgery, UCL Eastman Dental Institute, London, UK. ${ }^{3}$ Department of Surgery, UCL Medical School, London, UK. ${ }^{4}$ Academic Department of Trauma and Orthopaedic Surgery, Leeds Teaching Hospitals NHS Trust, Leeds, UK. ${ }^{5}$ Leeds Institute of Molecular Medicine, University of Leeds, Leeds, UK. 'Department of Oral and Maxillofacial Surgery, Chase Farm Hospital, Enfield, UK.

Received: 6 June 2012 Accepted: 7 June 2012

Published: 21 June 2012

\section{References}

1. Breine U, Brånemark PI: Reconstruction of alveolar jaw bone. An experimental and clinical study of immediate and preformed autologous bone grafts in combination with osteointegrated implants. Scand J Plast Reconstr Surg 1980, 14(1):23-48.

2. Chen ZW, Yan W: The study and clinical application of the osteocutaneous flap of fibula. Microsurgery 1983, 4(1):11-16. 
3. Chiapasco M, Abati S, Ramundo G, Rossi A, Romeo E, Vogel G: Behavior of implants in bone grafts or free flaps after tumor resection. Clin Oral Implants Res 2000, 11(1):66-75.

4. Chiapasco M, Biglioli F, Autelitano L, Romeo E, Brusati R: Clinical outcome of dental implants placed in fibula-free flaps used for the reconstruction of maxillo-mandibular defects following ablation for tumors or osteoradionecrosis. Clin Oral Implants Res 2006, 17(2):220-228.

5. Friberg B, Jemt T: Rehabilitation of edentulous mandibles by means of five TiUnite implants after one-stage surgery: a 1-year retrospective study of 90 patients. Clin Implant Dent Relat Res 2008, 10(1):47-54.

6. Hidalgo DA: Fibula free flap: a new method of mandible reconstruction. Plast Reconstr Surg 1989, 84(1):71-79.

7. Hidalgo DA, Rekow A: A review of 60 consecutive fibula free flap mandible reconstructions. Plast Reconstr Surg 1995, 96(3):585-596. discussion 597-602.

8. Hurst PS: Dental considerations in management of head and neck cancer. Otolaryngol Clin North Am 1985, 18(3):573-603.

9. Salibian AH, Rappaport I, Furnas DW, Achauer BM: Microvascular reconstruction of the mandible. Am J Surg 1980, 140(4):499-502.

10. Schliephake H, Schmelzeisen R, Husstedt H, Schmidt-Wondera LU: Comparison of the late results of mandibular reconstruction using nonvascularised or vascularised grafts and dental implants. J Oral Maxillofac Surg 1999, 57(8):944-950. discussion 950-1.

11. Schusterman MA, Horndeski G: Analysis of the morbidity associated with immediate microvascular reconstruction in head and neck cancer patients. Head Neck 1991, 13(1):51-55.

12. Urken ML, Vickery $C$, Weinberg $H$, Buchbinder D, Lawson W, Biller HF: The internal oblique-iliac crest osseomyocutaneous free flap in oromandibular reconstruction. Report of 20 cases. Arch Otolaryngol Head Neck Surg 1989, 115(3):339-349.

13. Vaughan ED, Bainton R, Martin IC: Improvements in morbidity of mouth cancer using microvascular free flap reconstructions. J Craniomaxillofac Surg 1992, 20(3):132-134.

14. Vaughan ED: The radial forearm flap in orofacial reconstruction. Int J Oral Maxillofac Surg 1994, 23(4):194-204.

15. Wolff KD, Ervens J, Herzog K, Hoffmeister B: Experience with the osteocutaneous fibula flap: an analysis of 24 consecutive reconstructions of composite mandibular defects. J Craniomaxillofac Surg 1996, 24(6):330-338.

16. Yaremchuk MJ: Vascularised bone grafts for maxillofacial reconstruction. Clin Plast Surg 1989, 16(1):29-39.

17. Hayter JP, Cawood Jl: Oral rehabilitation with endosteal implants and free flaps. Int J Oral Maxillofac Surg 1996, 25(1):3-12.

18. Kramer FJ, Dempf R, Bremer B: Efficacy of dental implants placed into fibulafree flaps for orofacial reconstruction. Clin Oral Implants Res 2005, 16 (1):80-88.

19. lizuka T, Häfliger J, Seto I, Rahal A, Mericske-Stern R, Smolka K: Oralrehabilitation after mandibular reconstruction using an osteocutaneous fibula free flap with endosseous implants. Factors affecting the functional outcome in patients with oral cancer. Clin Oral Implants Res 2005, 16(1):69-79.

20. Cordeiro PG, Disa JJ, Hidalgo DA, Hu QY: Reconstruction of the mandible with osseous free flaps: a 10-year experience with 150 consecutive patients. Plast Reconstr Surg 1999, 104(5):1314-1320.

21. Roumanas ED, Chang TL, Beumer J: Use ofosteointegratedimplants in the restoration of head and neck defects. J Calif Dent Assoc 2006, 34(9):711-718.

22. Gbara A, Darwich K, Li L, Schmelzle R, Blake F: Long-term results of jaw reconstruction with microsurgical fibula grafts and dental implants. $J$ Oral Maxillofac Surg 2007, 65(5):1005-1009.

23. Frodel JL Jr, Funk GF, Capper DT, Fridrich KL, Blumer JR, Haller JR, Hoffman HT: Osteointegratedimplants: a comparative study of bone thickness in four vascularised bone flaps. Plast Reconstr Surg 1993, 92(3):449-455. discussion 456-8.

24. Kürkcü M, Benlidayi ME, Kurtoğlu C, Kesiktaş E: Placement of implants in the mandible reconstructed with free vascularized fibula flap: comparison of 2 cases. Oral Surg Oral Med Oral Pathol Oral Radiol Endod 2008, 105(3):e36-e40.

25. Lee H, Ercoli C, Fantuzzo JJ, Girotto JA, Coniglio JU, Palermo M: Oral rehabilitation of a 12-year-old patient diagnosed with a central giant cell granuloma using a fibula graft and an implant-supported prosthesis: a clinical report. J Prosthet Dent 2008, 99(4):257-262.

26. Kunkel M, Wahlmann U, Reichert TE, Wegener J, Wagner W: Reconstruction of mandibular defects following tumor ablation by vertical distraction osteogenesis using intraosseous distraction devices. Clin Oral Implants Res 2005, 16(1):89-97.

27. Ruhin B, Menard P, Ceccaldi J, Dichamp J, Bertrand JC: Double-barrel fibular free flap for mandibular reconstruction: beneficial alternative for dental implanted rehabilitation (5 cases). Rev Stomatol Chir Maxillofac 2006, 107(5):338-344. discussion 345-6.

28. Nocini PF, Wangerin K, Albanese M, Kretschmer W, Cortelazzi R: Vertical distraction of a free vascularised fibula flap in a reconstructed hemimandible: case report. J Craniomaxillofac Surg 2000, 28(1):20-24.

29. Chiapasco M, Brusati R, Galioto S: Distraction osteogenesis of a fibular revascularised flap for improvement of oral implant positioning in a tumor patient: a case report. J Oral Maxillofac Surg 2000, 58(12):1434-1440.

30. Klesper B, Lazar F, Siessegger M, Hidding J, Zöller JE: Vertical distraction osteogenesis of fibula transplants for mandibular reconstruction-a preliminary study. J Craniomaxillofac Surg 2002, 30(5):280-285.

31. Rohner D, Bucher P, Kunz C, Hammer B, Schenk RK, Prein J: Treatment of severe atrophy of the maxilla with the prefabricated free vascularised fibula flap. Clin Oral Implants Res 2002, 13(1):44-52.

doi:10.1186/1758-3284-4-37

Cite this article as: Carbiner et al: Analysis of the compatibility of dental implant systems in fibula free flap reconstruction. Head \& Neck Oncology 2012 4:37.

\section{Submit your next manuscript to BioMed Central and take full advantage of:}

- Convenient online submission

- Thorough peer review

- No space constraints or color figure charges

- Immediate publication on acceptance

- Inclusion in PubMed, CAS, Scopus and Google Scholar

- Research which is freely available for redistribution

Submit your manuscript at www.biomedcentral.com/submit 